\title{
Characterisation of hexon and fibre genes of a novel strain of adenovirus involved in epidemic keratoconjunctivitis
}

\author{
A K Adhikary, T Inada, J Numaga, E Suzuki, H Ushiijima, U Banik, A Mukouyama, S Matsuno, \\ N Okabe
}

Aims: To characterise a novel strain (M86) of adenovirus (Ad) involved in epidemic keratoconjunctivitis (EKC).

Methods/Results: The virus strain was neutralised by antisera to both $\mathrm{Ad} 35$ and $\mathrm{Ad} 11$. Restriction endonuclease analysis of genomic DNA showed $98 \%$ and $88 \%$ homology with $\mathrm{Ad} 11$ and Ad35, respectively. The deduced amino acid sequence of the hypervariable regions of (HVRs) of the hexon gene showed a higher homology with Ad35 (94.4\%) than with $\operatorname{Ad} 11$ (83.7\%). However, it was 100\% homologous to Ad35 in HVRs 1, 2, 3, and 6 and to Ad1 1 in HVRs 4 and 6. In the fibre knob, the isolate was more homologous to Ad1 1 (99.4\%) than to Ad35 (29.1\%).

Conclusion: This novel strain of adenovirus showed similarities with both $\mathrm{Ad} 11$ and $\mathrm{Ad} 35$. The isolation of a novel strain like $A d 35+11$ is important because of its association with EKC.

\footnotetext{
A denovirus type 11 (Adll) and adenovirus type 35 (Ad35) belong to subgenus B2, and cause opportunistic infections mainly among the immunocompromised patients. ${ }^{1}$ Ad35 was isolated for the first time from a renal transplant recipient with interstitial pneumonia, ${ }^{2}$ whereas Adll was isolated from a faecal specimen of a child with poliomyelitis. ${ }^{3}$ Here, we report the isolation of a novel strain of adenovirus from a 25 year old otherwise healthy male patient with severe clinical manifestations of epidemic keratoconjunctivitis (EKC) in southern Japan.
}

\section{METHODS AND RESULTS}

Immunochromatography confirmed the causative agent as adenovirus (strain M86). ${ }^{4}$ Conjunctival scrapings were isolated in A549 cells and the viral titre was also determined in a microtitre plate containing a confluent monolayer of A549 cells. Aliquots $(25 \mu \mathrm{l})$ of 100 tissue culture infectious doses of virus $\left(\right.$ 100TCID $\left._{50}\right)$ were incubated with $25 \mu \mathrm{l}$ of serially diluted type specific antisera at $37^{\circ} \mathrm{C}$ for 60 minutes and then inoculated into A549 cells. Viral growth was inhibited by two different type specific antisera, anti-Adll and anti-Ad35, at a 256-fold dilution, and the strain was identified as Ad35+11. Although Adll infrequently causes keratoconjunctivitis, Ad35 or a novel strain like M86 $\left(\right.$ Ad35+11) has never been reported as an ocular pathogen. ${ }^{5}$ Therefore, this strain was subjected to a detailed study at the molecular level.

Viral DNA extraction and restriction endonuclease analysis of M86 with BamHI, BglII, BstEII, EcoRI, HindIII, PstI, SalI, SmaI, XbaI, and XhoI (Boehringer Mannheim, Mannheim, Germany) were carried out to investigate homology with the serologically related prototypes (Ad35 and Ad11), as described previously. ${ }^{6}$ Genomic homology between M86, Ad35, and Ad11 was calculated from published restriction patterns of Ad11, Ad35, and M86, using the percentage of pair wise co-migrating restriction fragments of a pair divided by the total number of bands in the pair. The isolate (M86) showed 98\% and 88\% homology with Adll and Ad35, respectively (fig 1). Higher homology of the new strain in restriction endonuclease analysis with $\operatorname{Ad} 35$ and $\operatorname{Ad} 11$ provide supportive evidence that the new strain might have evolved from the recombination of these two parent viruses. ${ }^{7}$

The fibre knob enables the virus to attach to the cellular receptor and, together with the hexon protein, defines the serological specificity of the adenoviruses. Therefore, the hexon gene and the fibre gene were analysed to compare the immunological data with the molecular biological results, in addition to looking for any possible variation that might be related to ocular pathogenicity. The hypervariable regions

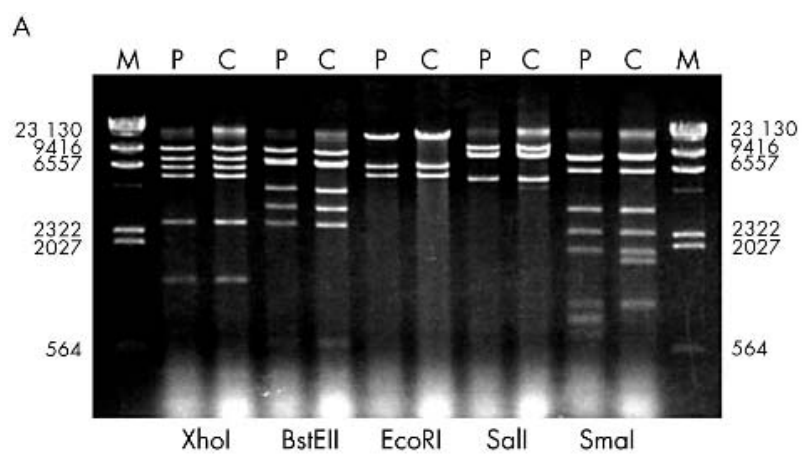

B

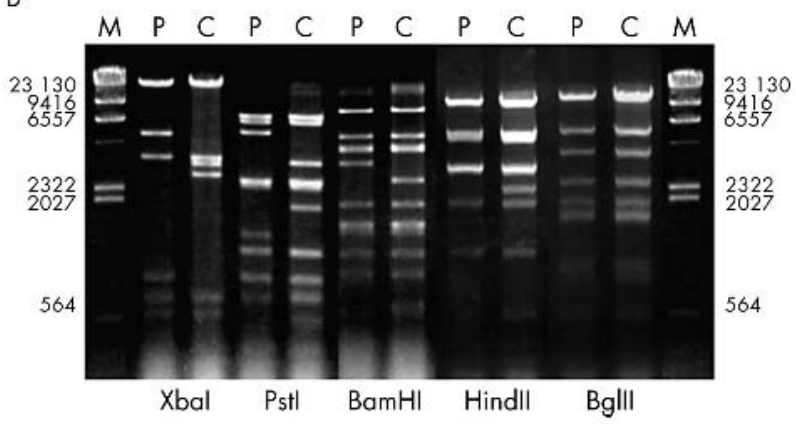

Figure 1 Restriction patterns obtained after cleavage of $\mathrm{Ad} 35 \mathrm{p}(\mathrm{P})$ and M86 (C). (A) Restriction endonucleases Xhol, BstEll, EcoRI, Sall, and Smal; (B) Xbal, Pstl, BamHI, Hindlll, and Bglll. The samples were electrophoresed on a $1.2 \%$ agarose gel. A Hindlll digest of $\lambda$ DNA (lane M) was run as a molecular weight standard.

Abbreviations: $\mathrm{AA}$, amino acid; $\mathrm{Ad}$, adenovirus; $\mathrm{EKC}$, epidemic keratoconjunctivitis; HVR, hypervariable region 
Table 1 Hexon gene amino acid homologies (\%) of M86 with other members of subgenus $B$ and subgenus $D$

\begin{tabular}{lrrrrrrrl}
\hline Ad & HVR1 & HVR2 & HVR3 & HVR4 & HVR5 & HVR6 & HVR7 & Overall \\
\hline Ad3 & 11.7 & 36.8 & 33.3 & 28.5 & 12.5 & 36.3 & 20.0 & 56.5 \\
Ad7 & 11.7 & 41.1 & 33.3 & 38.0 & 31.2 & 50.0 & 16.2 & 61.2 \\
Ad11 & 45.4 & 50.0 & 86.6 & 100.0 & 87.5 & 100.0 & 85.0 & 86.7 \\
Ad34 & 48.9 & 50.0 & 100.0 & 28.5 & 62.5 & 50.0 & 15.3 & 70.7 \\
Ad35 & 100.0 & 100.0 & 100.0 & 42.8 & 87.5 & 100.0 & 95.0 & 94.4 \\
Ad8 & 12.7 & 9.5 & 12.1 & 42.2 & 12.5 & 41.6 & 10.0 & 51.3 \\
Ad19 & 10.8 & 22.2 & 18.1 & 28.5 & 25.0 & 66.6 & 10.0 & 53.2 \\
Ad37 & 10.8 & 41.1 & 18.1 & 25.0 & 10.6 & 66.6 & 10.0 & 52.7 \\
\hline
\end{tabular}

Per cent of homology between the indicated hypervariable regions (HVRs) of M86 and the HVRs of adenovirus (Ad) subgenus B and subgenus $D$.

(HVRs) of the hexon gene and all regions of the fibre gene were sequenced by overlapping primers from genomic DNA by direct cycle sequencing. Multiple sets of primers for the hexon and fibre genes were selected based on alignment of the hexon gene (x76549 (Ad3), x76551 (Ad7), AB018424 (Adl1), AB018425 (Ad14), x74662 (Ad16), AY008279 (Ad21), AB018246 (Ad34), and AB018427 (Ad35)) and fibre gene sequences (m12411 (Ad3), m23696 (Ad7), L08231 (Ad11), AB065116 (Ad14), u06106 (Ad16), u06107 (Ad21), ul0271 (Ad34), and ul0272 (Ad35)) available from GeneBank. The sequences were determined by a Genetic Analyser 310 (Applied Biosystem, Foster City, California, USA). DNASIS software (Hitachi Software Ltd, Tokyo, Japan) was used for sequence alignment and analysis. The amino acid (AA) sequences of these residues were deduced. The AA sequences of M86 were compared with the available sequences of Ad3, Ad7, Ad11, Ad34, Ad35, Ad8, Ad19a, and Ad37 involved in keratoconjunctivitis. The nucleotide sequence data reported in our paper will appear in the DDBJ/GeneBank nucleotide sequence database with the accession numbers AB098564 (hexon gene) and AB098563 (fibre gene).
Table 2 Fibre gene nucleotide and amino acid homologies (\%) of M86 with other members of adenovirus (Ad) subgenus $B$ and subgenus $D$

\begin{tabular}{llllllll}
\hline & Ad11 & Ad34 & Ad35 & Ad3 & Ad7 & Ad8 & Ad19/37 \\
\hline Tail & & & & & & & \\
DNA & 100.0 & 99.2 & 99.2 & 80.6 & 97.6 & 48.8 & 48.0 \\
$\begin{array}{c}\text { Protein } \\
\text { Shaft }\end{array}$ & 100.0 & 97.6 & 97.6 & 86.0 & 97.6 & 37.2 & 30.0 \\
DNA & 98.1 & 71.7 & 71.7 & 55.2 & 90.1 & 32.9 & 31.8 \\
$\begin{array}{c}\text { Protein } \\
\text { Knob }\end{array}$ & 98.9 & 63.7 & 63.7 & 52.2 & 91.2 & 16.4 & 15.3 \\
DNA & 99.8 & 45.0 & 45.4 & 50.6 & 93.7 & 27.9 & 32.2 \\
Protein & 99.4 & 28.9 & 29.1 & 28.8 & 91.6 & 8.3 & 10.6 \\
Overall & & & & & & & \\
DNA & 99.3 & 59.7 & 59.9 & 56.3 & 93.2 & 30.4 & 34.1 \\
Protein & 99.3 & 47.8 & 47.8 & 41.8 & 92.3 & 12.6 & 12.6 \\
\hline
\end{tabular}

Per cent of homology between different fibre regions of $M 86$ and those of adenovirus (Ad) subgenus B and subgenus $D$.

In HVRs of the hexon, M86 showed an overall 94.4\% AA homology with Ad35 and 86.7\% with Adll (table 1). However, it was $100 \%$ homologous to Ad35 in HVRs 1, 2, 3 , and 6 and to Adll in HVRs 4 and 6 (fig 2). The fibre knob showed high AA homology (99.4\%) with Adll, but only 29.1\% homology with Ad35 (table 2).

\section{DISCUSSION}

Members of subgenus D adenoviruses (Ad8, Ad19, and Ad37) are the common agent of EKC. Occasionally, the members of subgenus B ( $\mathrm{Ad} 3$ and $\mathrm{Ad} 7)$ and subgenus E ( $\mathrm{Ad} 4)$ are also related to EKC. The tropism of adenoviruses for conjunctival or corneal cells depends on the presence of certain amino acids in the knob, which attaches the virus to the specific cellular receptor. ${ }^{8}$ The fact that the fibre knob of M86 has 99.4\% homology with Ad 11, with only a single AA difference, but only $29.1 \%$ homology with Ad35, means that it is able to attach to conjunctival and corneal cells (fig 3).
$\mathrm{L} 1<$

$\operatorname{Ad} 35$

M86

Ad 11

$\operatorname{Ad} 35$

M86

Ad 11

Ad35

M86

Ad 11

Ad35

M86

Ad 11

$\operatorname{Ad} 35$

M86

Ad 11

Ad35

M86

Ad 11

Ad35

M86

Ad 11

Ad35

M86

Ad 11 $>$

101

101
101$$
<
$$
$>$ L2< SGTAYNSLAP KGAPNASQWI AKGVPTAAAA GNGEEEHETE EKTATYTFAN SGTAYNSLAP KGAPNASQWI AKGVPTAAAA GNGEEEHETE EKTATYTFAN SGTAYNSLAP KGAPNTSQWI AEGVKNTTGE EHVTEE---E TNTTTYTFGN $>\quad$ HVR $2>$ HVR 3

51 APVKAEAQIT KEGLPIGLEI SAENESKPIY ADKLYQPEPQ VGDETWTDLD 51 APVKAEAQIT KEGLPIGLEI SAENESKPIY ADKLYQPEPQ VGDETWTDLD 51 APVKAEAEIT KEGLPVGLEV S-DEESKPIY ADKTYQPEPQ LGDETWTDLD

$$
<
$$$$
\text { HVR } 4
$$

GKTEEYGGRA LKPTTNMKPC YGSYAKPTNL KGGQAKPKNS EPSSEKIEYD GKTEEYGGRA LKPDTKMKPC YGSFAKPTNV KGGQAKQKTT EQPNQKVEYD GKTEKYGGRA LKPDTSMKPC YGSFAKPTNV KGGQAKOKTT EOPNOKVEYD HVR 5 $>$ IDMEFFDNSS ORTNFSPKIV MYAENVGLET PDTHVVYKPG TEDTSSEANI 151 IDMEFFDAAS QRTNFSPKIV MYAENVGLET PDTHVVYKPG TEDTSSEANL

201 GQQSMPNRPN YIGFRDNFIG LMYYNSTGNM GVLAGQASQL NAVVDLQDRN 201 GQQSMPNRPN YIGFRDNFIG LMYYNSTGNM GVLAGQASQL NAVVDLQDRN 201 GQQSMPNRPN YIGFRDNFIG LMYYNSTGNM GVLAGQASQL NAVVDLQDRN

251 TELSYQLLLD SLGDRTRYFS MWNQAVDSYD PDVRVIENHG VEDELPNYCF 251 TELSYQLLLD SLGDRTRYFS MUNOAVDSYD PDVRVIFNHG VEDELPNYCF 251 TELSYQLLLD SLGDRTRYFS MWNQAVDSYD PDVRVIENHG VEDELPNYCF HVR 7

301 PLDGIGVPTT SYKSIVPNGE DNNNWKEPEV NGTSEIGQGN LFAMEINLQA 301 PLNGIGVPTT SYKSIVPNGE DNNNWKEPEV NGTSEIGQGN LSAMEINLQA 301 PLDGIGVPTT SYKSIVPNGD NAPNWKEPEV NGTSEIGQGN LFAMEINLQA
NLWRSFLY .

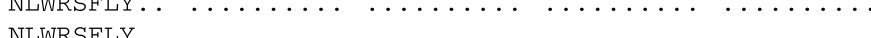

Figure 2 Comparison of predicted amino acid sequences of seven hypervariable regions (HVRs) of M86 with that of adenovirus type 11 (Ad1 1) and Ad35. The sequences of loop 1 (L1) and loop 2 (L2) were aligned to obtain maximal homology. Deduced amino acid sequences of $\mathrm{Ad} 11$ and $\mathrm{Ad} 35$ were obtained from GeneBank accession numbers $\mathrm{ABO} 18424$ (Ad1 1) and $A B O 18427(A d 35))$.

\section{(1)}

(1) . .

.




\begin{tabular}{|c|c|c|c|c|c|c|c|c|}
\hline M86 & 1 & WTGVNPTEAN & CQIMNSSESN & DCKLILTLVK & TGALVTAFVY & VIGVSNNFNM & 50 & \\
\hline Adl 1 & 1 & WTGVNPTEAN & CQIMNSSESN & DCKLILTLVK & TGALVTAFVY & VIGVSNNFNM & 50 & fibre knob sequences of $M 86$ \\
\hline Ad35 & 1 & WTGINPP-PN & CQIVENTNTN & DGKLTLVLVK & NGGLVNGYVS & LVGVSDTVNQ & 50 & $\begin{array}{l}\text { adenovirus type } 11 \mathrm{p}(\mathrm{Ad} 11 \mathrm{p}) \text {, and } \\
\text { Ad35p. The sequences were aligned to }\end{array}$ \\
\hline M86 & 51 & LTTHRNINFT & AELFFDSTGN & LLTRLSSLKT & PLNHKSGQNM & ATGAITNAKG & 100 & obtain maximal homology. The \\
\hline Adl1 1 & 51 & LTTHRNINFT & AELFFDSTGN & LLTRLSSLKT & PLNHKSGQNM & ATGAITNAKG & 100 & deletions are represented by dashes. \\
\hline Ad35 & 51 & MFTQKTANIQ & LRLYFDSSGN & LLTEESDLKI & PLKNKSSTA- & TSETVASSKA & 100 & $\begin{array}{l}\text { Deduced amino acid sequences of } \\
\text { Ad } 11 p \text { and } A d 35 p \text { were obtained from }\end{array}$ \\
\hline M86 & 101 & FMPSTTAYPF & NDNSREKENY & IYGTCYYAAS & -DRTAFPIDI & SVMLNRRAIN & 150 & GeneBank (accession numbers L08231 \\
\hline Adl1 1 & 101 & FMPSTTAYPF & NDNSREKENY & IYGTCYYTAS & -DRTAFPIDI & SVMLNRRAIN & 150 & (Ad1 1p) and U10272 (Ad35p)). \\
\hline Ad35 & 101 & FMPSTTAYPF & NTTTRDSENY & IHGICYYMTS & YDRSLFPLNI & SIMLNSRMIS & 150 & \\
\hline & 151 & DETSYCIRIT & WSWNTGDAPE & VQTSATTLVT & SPFTFYYIRE & & & \\
\hline & 151 & DETSYCIRIT & WSWNTGDAPE & VQTSATTLVT & SPFTFYYIRE & DD. & 20 & \\
\hline Ad & 151 & SNVAYAIQFE & WNLNASESPE & --SNIATLTT & SPFFFSYITE & DD... & 200 & \\
\hline
\end{tabular}

Neutralisation of the infectivity of adenoviruses is primarily carried out by antibodies against the hexon protein. Antigenic determinants (epitopes) located in two or more of the seven HVRs in loop 1 and loop 2 of the hexon react with neutralising antibodies. ${ }^{9}$ These HVRs are highly conserved within the serotype. ${ }^{10}$ However, the position of the epitope in the HVRs and number of amino acids forming them are yet to be determined. The construction of a chimaera in the HVRs of the hexon could change the antigenic specificity of the virus, enabling it to escape type specific neutralisation. ${ }^{11}$ M86 was $100 \%$ homologous to Ad35 in HVRs 1, 2, 3, and 6 and to Ad 11 in HVRs 4 and 6 . This sequence variation reflects the preceding mutation or recombination events involving the HVRs of the hexon, which is expressed by a mixed antigenic character in the neutralisation test. This novel arrangement in the HVRs might enable the virus to circumvent existing immunity.

"The construction of a chimaera in the hypervariable regions of the hexon could change the antigenic specificity of the virus, enabling it to escape type specific neutralisation"

The isolation of a strain like M86 as a new aetiological agent of EKC is medically and epidemiologically important because it shows that recombination or mutation involving the HVRs of the hexon gene can enable the non-ocular adenoviruses to become ocular pathogens. It is also possible that such strains can circumvent existing immunity and

\section{Take home messages}

- We have characterised a novel strain (M86) of adenovirus (Ad) involved in epidemic keratoconjunctivitis

- The virus strain showed homology with both $\mathrm{Ad} 35$ and Ad1 1 using both immunological and molecular biological techniques

- It high homology with the fibre knob sequences of Ad1 1 may provide it with the ability to invade ocular cells

- The mixed antigenic characteristics of virus strains such as this may enable them to circumvent existing immunity might be responsible for outbreaks of EKC in the future; this may be especially important in developing countries, where the detection of adenoviruses in the clinical setting is not available. It is also important to accumulate data on the HVRs of the hexon gene and fibre gene sequences of the EKC strains to predict their possible role in keratoconjunctivitis.

\section{ACKNOWLEDGEMENTS}

Supported by grant-in-aid for Scientific Research from the Japan Society for the Promotion of Science (JSPS), Japan.

\section{Authors' affiliations}

A K Adhikary, T Inada, U Banik, A Mukouyama, S Matsuno, N Okabe, Infectious Disease Surveillance Centre, National Institute of Infectious

Diseases, 1-23-1 Toyama, Shinjuku-ku, Tokyo 162-8640, Japan

J Numaga, Department of Ophthalmology, Graduate School of Medicine, The University of Tokyo, 7-3-1 Hongo, Bunkyo-ku, Tokyo 1130033, Japan

E Suzuki, H Ushijima, Department of Developmental Medical Sciences, Graduate School of Medicine, The University of Tokyo

Correspondence to: Dr A K Adhikary, Mailing, Infectious Disease Surveillance Centre, National Institute of Infectious Diseases, 1-23-1

Toyama, Shinjuku-ku, Tokyo 162-8640, Japan; arun@nih.go.jp

Accepted for publication 10 July 2003

\section{REFERENCES}

1 Hierholzer JC. Adenoviruses in the immunocompromised host. J Clin Microbiol 1992:5:262-74.

2 Stalder $\mathrm{H}$, Hierholzer JC, Oxman MN. New human adenovirus (candidate adenovirus type 35 ) causing fatal disseminated infection in a renal transplan recipient. J Clin Microbiol 1977;6:257-65.

3 Kibrick S, Melendez L, Ender JF. Clinical association of enteric viruses with particular reference to agents exhibiting properties of ECHO group. Ann NY Acad Sci 1957;67:311-29.

4 Uchio E, Aoki K, Saitoh W, et al. Rapid diagnosis of adenoviral conjunctivitis on conjunctival swab by 10-minute immunochromatography. Ophthalmology 1996:104:1294-9.

5 Kitamura N. Genome analysis of adenovirus type 7 and adenovirus type 11. Jpn J Opthalmol 2001;45:22-30.

6 Adhikary AK, Numaga J, Kaburaki T, et al. Genetic characterisation of adenovirus type 8 isolated in Hiroshima city over a 15 year period. J Clin Pathol 2003;56:120-5.

7 Sambrook J, Sleigh M, Engler JA, et al. The evolution of the adenoviral genome. Ann NY Acad Sci 1980;354:426-52.

8 Eiz B, Adrian T, Pring-Akerblom P. Recombinant fiber proteins of human adenoviruses Ad9, Ad15 and Ad19: localization of the haemagglutination properties and the type specific determinant. Res Virol 1997; 148:5-10.

9 Crawford-Miksza L, Schnurr DP. Analysis of adenovirus hexon proteins revealed the location of structure of seven hypervariable regions containing serotype-specific residues. J Virol 1996:70:1835-40.

10 Li QG, Wadell G. Genetic variability of hexon loops 1 and 2 between seven genome types of adenovirus 7. Arch Virol 1999;144:1739-49.

11 Roy S, Shirley PS, McClelland A, et al. Circumvention of immunity to the adenovirus major coat protein hexon. J Virol 1998;72:6875-9. 